\title{
PENGARUH KETERAMPILAN MANAJERIAL, KOMUNIKASI INTERPERSONAL DAN BUDAYA MUTU TERHADAP ORGANIZATIONAL CITIZENSHIP BEHAVIOR
}

\author{
Surasni ${ }^{1)}$ \\ 1) dosen universitas pamulang, email : niniek.yoga@yahoo.com
}

\section{ARTICLES INFORMATION}

\section{ABSTRACT}

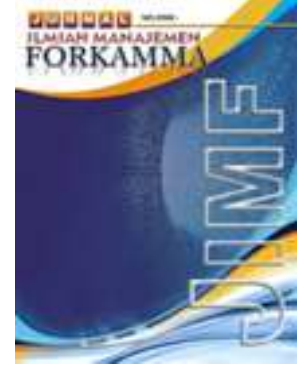

\section{JURNAL ILMIAH MANAJEMEN FORKAMMA}

\author{
Vol.1, No.3, Mei 2017 \\ Halaman : $33-47$ \\ (C) LPPM \& PORKAMMA
}

Prodi Magister Manajemen UNVERSITAS PAMULANG

ISSN (online) : 2599-171X ISSN (print) : :2598-9545

\section{Keyword :}

Keterampilan manajerial, komunikasi interpersonal

JEL. classification :

C31, E50

\section{Contact Author : \\ PRODI \\ MAGISTER MANAJEMEN \& FORKAMMA UNPAM \\ JL.Surya Kencana No.1 Pamulang \\ Tangerang Selatan - Banten \\ Telp. (021) 7412566, Fax (021) 7412491 \\ Email : \\ jurnalforkamma.unpam@gmail.com}

Objektif penelitian adalah menentukan pengaruh langsung dari keterampilan manajerial, komunikasi interpersonal dan budaya mutu terhadap perilaku anggota organisasi pada guru sekolah dasar negeri Kabupaten Lampung Utara. Metode penelitian menggunakan pendekatan kuantitatif dengan metode survei dan teknik analisis jalur. Data dikumpulkan menggunakan kuesioner kepada 205 guru sebagai sampel dari populasi target sebanyak 419 guru. Teknik sampling menggunakan teknik acak proporsional. Analisis data menggunakan statistik deskriptif dan statistik inferensial. Hasil penelitian adalah: 1) Keterampilan manajerial, komunikasi interpersonal dan budaya mutu mempunyai pengaruh positif langsung terhadap perilaku anggota organisasi;2) Keterampilan manajerial mempunyai pengaruh positif langsung terhadap budaya mutu dan komunikasi interpersonal.Jadi, untuk meningkatkan perilaku anggota organisasi, dilaksanakan dengan memperbaiki keterampilan manajerial, komunikasi interpersonal dan budaya mutu.

The objectives of the research was to determine the direct effect of managerial skill, interpersonal communication and quality culture toward organizational citizenship behavior of teachers at public elementary school in North Lampung regency. The research method uses a quantitative approach with the survey methods, and path analysis technique. The data was collected by distributing questionnaires to 205 teachers as samples from the target population of 419 teachers. Sampling technique are with proportional random sampling. Data analysis using descriptive statistics and inferential statistics. The result of the research are:1) Managerial skill, interpersonal communication and quality culture have a direct positive effect toward organizational citizenship behavior; 2) Managerial skill has a direct positive effect toward quality culture and interpersonal communication. So, to increase organizational citizenship behaviorcan be carried out by improving managerial skill, interpersonal communication and quality culture. 


\section{A. Pendahuluan}

Pembangunan nasional di bidang pen-didikan merupakan upaya mencerdaskan kehidupan bangsa dan meningkatkan kualitas manusia Indonesia dalam me-wujudkan masyarakat yang maju, adil dan makmur. Untuk mencapai tujuan tersebut diperlukan berbagai upaya. Salah satu upaya yang sedang dilaksanakan Pemerintah adalah meningkatkan mutu dan profesionalitas kepala sekolah sebagai pemimpin institusi dan pemimpin manajemen.

Setiap organisasi termasuk organisasi sekolah membutuhkan perilaku OCB yang terdapat dalam diri para karyawannya dalam hal ini guru. Guru yang memiliki OCB akan memiliki loyalitas yang tinggi terhadap organisasi tempatnya bekerja dan dengan sendirinya akan merasa nyaman dan aman terhadap pekerjaannya. Lebih lanjut Sweeney dan McFarlin (2002: 61) menyatakan bahwa OCB is these voluntary, above the call of duty behaviors that some feel not only contribute to company success but are necessary for success. Definisi tersebut mengandung arti bahwa OCB merupakan kesukarelaan, suatu perilaku yang me-lebihi panggilan tugas, dimana beberapa orang merasa bahwa hal tersebut bukan hanya dapat memberikan kontribusi bagi keberhasilan organisasi namun juga mereka butuhkan untuk keberhasilan mereka sendiri.

Guru diharapkan tidak hanya mengerjakan tugas pokoknya saja namun mau memberikan pelayanan ekstra kepada pengguna layanan, menolong, bertoleransi, secara sukarela me-laksanakan tugas di luar jam kerjanya, memiliki inisiatif untuk mengembangkan diri, aktif dalam memajukan sekolah serta mampu menggunakan waktu kerja secara efektif. Guru dengan perilaku positif tersebut di atas dapat diartikan memiliki OCB yang tinggi. Pernyataan ini sesuai dengan pendapat Colquit (2009: 43-44), OCB is voluntary employee activities that may or may not be rewarded but that contribute to the organization by improving the overall quality of the setting in which work takes place. Pendapat ini menjelaskan bahwa OCB adalah kegiatan yang dilakukan oleh karyawan dengan sukarela baik dihargai maupun tidak tetapi sangat berkontribusi terhadap peningkatan kualitas dan keber-langsungan pengaturan pekerjaan dalam organisasi.

Seorang kepala sekolah harus me-miliki beberapa keterampilan yang men-dukung keberhasilan dalam me-laksanakan pekerjaannya. Keterampilan manajerial yang rendah dapat me-nyebabkan kepala sekolah tidak dapat mengelola organisasi sekolah dengan optimal sehingga dapat menyebabkan gagalnya tujuan organisasi sekolah. Menurut John A. Wagner dan John R. Hollenbeck (2010: 20) mendefinisikan ke-terampilan manajerial sebagai berikut Managerial skill is the skills that managers use to succeed in their jobs are largely determined by the combination of planning, organizing, directing, and controlling functions that they must perform. Berdasarkan kutipan di atas bahwa keterampilan manajerial me-rupakan keterampilan yang digunakan para manajer untuk mensukseskan pekerjaan-pekerjaan mereka yang sebagian besar ditentukan oleh kombinasi dari merencanakan, mengorganisasikan, arahan, dan mengontrol fungsi-fungsi yang harus mereka lakukan.

Sedangkan berdasarkan pendapat Chen et. al. (2005: 786) bahwa managerial skill utilization may determine organizational outcomes and performance, such as job performance and organizational citizenship behaviour, job attitudes, job satisfaction, organizational commitment, work morale and efficiency, and management development. $\mathrm{Hal}$ ini berarti bahwa manfaat keterampilan manajerial me-nentukan keluaran dan kinerja organisasional, seperti kinerja dan OCB (perilaku anggota organisasi), sikap dalam bekerja, kepuasan kerja, komitmen organisasional, moral dan efisiensi pekerjaan, serta perkembangan manajemen.

Komunikasi dalam organisasi me-rupakan salah satu unsur yang sangat penting demi terciptanya tujuan organisasi dalam hal ini sekolah. Luthans (2011: 249) menyatakan bahwa communication used in organizational behavior literature stress the use of symbols to transfer the meaning of information and also the fact that communication is a personal 
process that involves the exchange of behaviors and information. Berdasarkan kutipan di atas bahwa komunikasi yang digunakan dalam literatur perilaku organisasional menekankan pada penggunaan simbol-simbol untuk mentransfer arti dari informasi dan juga fakta bahwa komunikasi adalah proses pribadi yang melibatkan pertukaran perilaku dan informasi. Artinya, dalam komunikasi tujuannya adalah untuk memindahkan informasi dan pengertian dari satu orang atau kelompok orang kepada orang atau kelompok lain. Tujuan pemindahan ini untuk mendapatkan informasi dari satu orang atau kelompok terhadap orang atau kelompok lainnya.

Komunikasi interpersonal menjadi sangat penting dalam organisasi di-sebabkan masing-masing anggota mem-butuhkan informasi yang saling me-manfaatkan dan mendukung suatu pe-kerjaan yang sukses untuk mencapai kinerja yang diinginkan. Demikian halnya dengan keterampilan manajerial kepala sekolah harus mampu menyerap berbagai input informasi yang berasal dari komunikasi interpersonal untuk meng-hasilkan output yang menjadi target untuk mencapai tujuan.

Kepala sekolah sebagai pemimpin pendidikan harus memiliki dan memahami bahasa komunikasi yang baik dan benar karena dapat membantu keberhasilan dalam menjalankan tugasnya sebagai penentu kebijakan. Komunikasi interpersonal menurut Mulyasa (2002: 73) adalah komunikasi antara orang-orang secara tatap muka, yang memungkinkan setiap pesertanya menangkap reaksi orang lain secara langsung, baik secara verbal atau non verbal. Pada akhirnya proses komunikasi dikatakan pula sebagai proses yang bersifat psikologis karena merupakan awal terbentuknya ikatan psikologis antar manusia dan memberikan peluang bakal terbentuknya kebersamaan dalam kelompok yang tidak lain merupakan tanda adanya proses sosial. Keharmonisan yang tercipta dari efektifnya komunikasi interpersonal dalam proses nantinya akan memberikan dampak terhadap kelancaran pe-laksanaan tugas setiap orang dalam kelompok kerjanya.

Berbagai upaya untuk meningkatkan mutu pendidikan kini sebenarnya telah, sedang dan akan terus dilaksanakan secara bertahap dan berkelanjutan. Mulai dari peningkatan kualitas pendidikan pra sekolah, dasar, menengah sampai dengan perguruan tinggi. Pengelolaan pendidikan berbasis manajemen mutu lebih menekankan pada kemandirian, kreativitas sekolah dan perbaikan proses yang lebih dijiwai oleh budaya mutu.

Sekolah bertanggungjawab atas mutu pendidikan kepada pemerintah, orang tua peserta didik, masyarakat, dan customer pendidikan. Disinilah pentingnya mem-bangun budaya mutu sebagai sebuah filosofi dan pijakan dasar sekolah dalam mengembangkan diri secara ber-kesinambungan. Budaya mutu menurut Katiliute dan Neverauskas (2009: 1069-1079) bahwa Quality culture is the main ingredient in a successful TQM program. Berarti bahwa budaya mutu merupakan kunci utama untuk mencapai kesuksesan dalam program manajemen mutu terpadu. Pendapat tersebut mengisyaratkan betapa pentingnya budaya mutu dalam menyukseskan TQM. Selanjutnya manajemen mutu terpadu tidak akan berjalan jika budaya mutu tidak ada dalam suatu lembaga pendidikan seperti sekolah.

Guna mendapatkan pemimpin sekolah yang sesuai dengan era kini diperlukan kejelian dalam menghadapi segala per-masalahan yang ada, di samping itu juga harus mempunyai kemampuan memimpin dan kemampuan intelektual yang tidak di-ragukan sehingga di dalam memutuskan suatu kebijakan dapat diterima baik oleh masyarakat luas maupun sekolah yang dipimpinnya.

Survei awal penulis lakukan dengan melakukan wawancara terhadap pengawas dan pejabat Dinas Pendidikan Kabupaten Lampung Utara yang memprediksi baru sekitar 60\% kepala sekolah SD Negeri yang memenuhi Permendiknas Nomor 13 Tahun 2007 tentang Standar Kompetensi Kepala Sekolah.

Menurut pengamatan penulis, beberapa faktor penyebab atas rendahnya mutu pendidikan di Kabupaten Lampung Utara diantaranya disebabkan sistem rekrutmen kepala sekolah yang di-lakukan oleh Pemerintah Daerah yang kurang sesuai dengan 
standar kualitas yang diharapkan, kurangnya pelatihan yang seharusnya dilakukan oleh Pemerintah Daerah, dan kurangnya ke-terampilan yang dimiliki oleh para kepala sekolah, khususnya keterampilan manajerial kepala sekolah. Selain itu kurangnya pengawasan yang dilakukan oleh Dinas Pendidikan Kabupaten serta kurang berperannya Lembaga Penjaminan Mutu Pendidikan (LPMP) yang ada pada tingkat provinsi.

Rendahnya Organizational Citizenship Behavior guru di sekolah berdampak pada keterampilan manajerial kepala sekolah dan komunikasi interpersonal di sekolah. Hal ini sesuai dengan hasil penelitian sebelumnya yang dilakukan oleh Chen et. al. (2005: 786808) berjudul Managerial Skill Utilization: Work Environment, Gender and Training Incentive. Penelitian ini menyatakan bahwa pemanfaatan keterampilan manajerial menentukan keluaran dan kinerja organisasional, salah satunya adalah Organizational Citizenship Behavior.

Guru memegang tugas ganda dalam proses pendidikan di sekolah yaitu sebagai pengajar dan pendidik. Pendidikan merupakan sesuatu yang harus diperhatikan kualitasnya, seperti yang kita ketahui untuk mendapatkan pendidikan yang berkualitas tentunya dibutuhkan tenaga pengajar yang memiliki peran organizational citizenship behavior. Namun, pada kenyataannya tingkat profesionalisme pengajar dalam membantu rekan kerjanya belum optimal.

Hal ini terlihat dari Guru SD Negeri di Kabupaten Lampung Utara juga mengalami realita bahwa adanya tuntutan pekerjaan dan tugas yang tinggi sementara masih adanya keterbatasan-keterbatasan reward dari tuntutan tersebut. Keadaan ini menuntut guru SD Negeri di Kabupaten Lampung Utara untuk melakukan aktivitas yang dilakukan secara sukarela dalam perilaku-perilaku yang melebihi persyaratan kerja formal (OCB).

Berdasarkan studi pendahuluan yang dilakukan peneliti pada guru SD Negeri di Kabupaten Lampung Utara dan didukung dengan hasil wawancara terhadap enam kepala sekolah SD Negeri di Kecamatan Kotabumi Selatan Kabupaten Lampung Utara yang dilakukan pada tanggal 30 dan 31 Agustus 2015 ditemukan indikasi yang menunjukkan OCB guru SD Negeri di Kecamatan Kotabumi Selatan belum optimal. Beberapa hal yang meng-indikasikan belum optimalnya OCB guru SD Negeri di Kecamatan Kotabumi Selatan tersebut adalah guru belum banyak terlibat dalam kegiatan ekstra kurikuler sekolah, guru kurang memahami etika pembelajaran, guru belum mempunyai inisiatif dan ide untuk mengembangkan potensinya (masih menunggu perintah kepala sekolah), guru kurang mencurahkan perhatiannya ke-pada anak didik, masih ada guru yang sering ijin, guru tidak memanfaatkan waktu secara efektif, dan guru belum mempersiapkan rencana pengajaran dengan baik.

Hasil wawancara dengan lima kepala sekolah lain di Kecamatan Kotabumi Kota Kabupaten Lampung Utara pada tanggal 1 dan 2 September 2015 teridentifikasi ada keterbatasan OCB guru, antara lain: kurangnya kesadaran ekstra untuk me-ningkatkan mutu pendidikan melalui proses pembelajaran yang berkualitas secara berkelanjutan, minimnya inovasi dalam memajukan sekolah, rendahnya sportivitas dalam menghadapi persoalan dan tantangan yang muncul di sekolah, serta terbatasnya kemauan berbuat ekstra yang terbaik untuk kepentingan sekolah dan kemajuan pendidikan. Kondisi seperti itu selaras dengan hasil Ujian Nasional (UN) tahun 2014/2015 yang belum maksimal, walaupun setiap tahun nilai UN terus meningkat, akan tetapi nilai rata-rata yang dicapai adalah 5,82 masih jauh dari harapan. Nilai tersebut jelas merupakan hasil yang sangat buruk dan kontraproduktif dengan spirit OCB.

Berdasarkan uraian di atas perlu di-adakan penelitian tentang variabel-variabel yang diduga berpengaruh terhadap Organizational Citizenship Behavior. Oleh karenanya peneliti tertarik untuk melakukan penelitian tentang "Pengaruh Keterampilan Manajerial, Komunikasi Interpersonal dan Budaya Mutu Terhadap Organizational Citizenship Behavior (Survei Pada Guru Sekolah Dasar Negeri di Kabupaten Lampung Utara)".

Berdasarkan latar belakang di atas, maka masalah yang dapat dirumuskan pada penelitian ini adalah sebagai berikut: 
1) Apakah terdapat pengaruh langsung keterampilan manajerial terhadap Organizational Citizenship Behavior (Perilaku Anggota Organisasi)?

2) Apakah terdapat pengaruh langsung komunikasi interpersonal terhadap Organizational Citizenship Behavior (Perilaku Anggota Organisasi)?

3) Apakah terdapat pengaruh langsung budaya mutu terhadap Organizational Citizenship Behavior (Perilaku Anggota Organisasi)?

4) Apakah terdapat pengaruh langsung keterampilan manajerial terhadap budaya mutu?

5) Apakah terdapat pengaruh langsung komunikasi interpersonal terhadap budaya mutu?

6) Apakah terdapat pengaruh langsung keterampilan manajerial terhadap komunikasi interpersonal?

\section{Kegunaan Penelitian}

Manfaat teoretis, hasil penelitian ini di-harapkan dapat memberikan sumbangan kepada pengembangan ilmu, terutama ilmu perilaku organisasi dan manajemen pendidikan di sekolah, serta menjadi pendukung bagi penelitian lain yang berkaitan dengan persoalan Organizational Citizenship Behavior (OCB).

Manfaat praktis dari penelitian ini adalah; (1) Memberikan sumbangan pe-mikiran kepada para guru tentang pengaruh keterampilan manajerial, komunikasi interpersonal, budaya mutu dan Organizational Citizenship Behavior (OCB), (2) Meningkatkan mutu sekolah melalui Organizational Citizenship Behavior (OCB) dalam kerangka keterampilan manajerial, komunikasi interpersonal dan budaya mutu, (3) Khususnya bagi mahasiswa doktoral Manajemen Pendidikan, penelitian ini menjadi gambaran bagaimana teori-teori manajemen pendidikan di-implementasikan dalam tatanan praktis dan menjadi umpan balik kesiapan praktisi pendidikan dalam meningkatkan mutu pendidikan.

\section{KAJIAN TEORITIK}

\section{Organizational Citizenship Behavior}

Pada dinamika kehidupan organisasi, khususnya organisasi nirlaba seperti organisasi kependidikan, diperlukan perilaku ekstra peran yang lazim disebut organizational citizenship behavior (OCB). Istilah lain OCB adalah extra-role behaviour.

Menurut Alotaibi (2001: 363), OCB is discretionary "pro-social" ethical behavior. Artinya, OCB adalah perilaku etis kebebasan memilih "pro-sosial". Perilaku seperti itu dibutuhkan untuk mendukung kegiatan-kegiatan dalam organisasi yang tidak selamanya dapat dilakukan secara formal melalui kegiatan-kegiatan rutin organisasional. Pada kondisi tertentu, adakalanya organisasi membutuhkan perilaku ekstra peran, terutama ketika organisasi memerlukan dukungan aktivitas pegawai yang tidak dapat dinilai atau dihargai dengan uang.

Colquit et al. (2009: 43-44), memberi pandangan tentang definisi OCB bahwa: "OCB is voluntary employee activities that may or may not be rewarded but that contribute to the organization by improving the overall quality of the setting in which work takes place". Pendapat ini menjelaskan bahwa OCB adalah kegiatan yang dilakukan oleh karyawan dengan sukarela baik dihargai maupun tidak tetapi sangat berkontribusi terhadap pe-ningkatan kualitas dan keberlangsungan pengaturan pekerjaan dalam organisasi.

Menurut Luthans (2011: 149) me-ngemukakan bahwa "OCBs can take many forms, but the major ones could be summarized as: 1) altruism, 2) conscientiousness, 3) civic virtue, 4) sportsmanship, and 5) courtesy". Hal ini berarti bahwa OCB dapat memiliki banyak bentuk, tetapi yang paling utama dapat disimpulkan sebagai berikut: 1) altruisme, 2) kesadaran, 3) kebajikan, 4) sportivitas, dan 5) kesopanan.

Berdasarkan uraian di atas dapat disintesiskan bahwa organizational citizenship behavior (OCB) adalah perilaku individu yang tidak tercantum dalam deskripsi pekerjaan yang mem-punyai manfaat positif terhadap organisasi dalam mencapai tujuan-tujuannya, 
dengan indikator: perilaku menolong, rasa hormat, sportivitas, kesungguhan, dan tanggung jawab sebagai anggota organisasi.

\section{Keterampilan Manajerial}

Keterampilan manajerial terdiri dari dua kata yaitu "keterampilan" dan "manajerial". Menurut Jennifer M George dan Gareth R. Jones (2012: 12) bahwa "Skill is an ability to act in a way that allows a person to perform well in his or her role". Hal ini berarti bahwa ke-terampilan adalah suatu kemampuan untuk bertindak dalam suatu cara yang membolehkan seseorang untuk bertindak dengan baik dalam peranannya.

Menurut John A. Wagner dan John R. Hollenbeck (2010: 20) mendefinisikan keterampilan manajerial sebagai berikut: "Managerial skill is the skills that managers use to succeed in their jobs are largely determined by the combination of planning, organizing, directing, and controlling functions that they must perform." Berdasarkan kutipan di atas bahwa keterampilan manajerial me-rupakan keterampilan yang digunakan para manajer untuk mensukseskan pekerjaan-pekerjaan mereka yang sebagian besar ditentukan oleh kombinasi dari merencanakan, mengorganisasikan, mengarahkan, dan mengontrol fungsi-fungsi yang harus mereka lakukan.

Sedangkan menurut Stephen P. Robbins dan Timothy A. Judge (2013: 8) bahwa "Managerial skill is another way of considering what managers do in order to look at the skills or competencies they need to achieve their goals." Berdasarkan kutipan di atas bahwa keterampilan manajerial merupakan cara lain dari mempertimbangkan apa yang para manajer lakukan agar melihat keterampilan-keterampilan atau kompetensikompetensi yang mereka butuhkan untuk mencapai sasaran mereka.

Menurut Chuadhry dan Shah (2012: 375) bahwa: Principal needs certain skills to perform his/her duties and activities associated with being a school head. The head needs skills that are technical, human and conceptual skills. Technical skills include knowledge of and proficiency in a certain specialized field, such as computers, financial and managerial accounting, or manufacturing. Human skills involve the ability to work well with other people both individually and in a group. Heads deal directly with people. Heads with good human skills are able to get the best out of their people. They should know how to communicate, motivate, lead, and inspire enthusiasm and trust. This is equally important at all levels of management. The conceptual skills those heads must have to think and conceptualize about abstract and complex situations. Using these skills heads must be able to see the organization as a whole, understand the relationship among various subunits, and visualize how the organization fits into its broader environment.

Berdasarkan kutipan di atas menyatakan bahwa kepala sekolah membutuhkan keterampilan-keterampilan tertentu untuk melaksanakan kewajiban dan aktivitasnya yang berhubungan dengan menjadi seorang pemimpin sekolah. Kepala sekolah membutuhkan keterampilan-keterampilan yang teknis, manusiawi dan konseptual. Keterampilan teknis termasuk pengetahuan dan kecakapan dalam suatu bidang khusus tertentu, seperti komputer, laporan keuangan dan manajerial, atau produksi. Keterampilan manusiawi meliputi ke-mampuan untuk bekerja secara baik dengan orang lain, baik individual maupun kelompok. Kepala sekolah ber-hubungan langsung dengan orang-orang. Kepala sekolah dengan keterampilan manusiawi yang baik mampu untuk mendapat hal yang terbaik dari orang lain. Mereka seharusnya mengetahui bagaimana berkomunikasi, memotivasi, memimpin, dan menginspirasi secara antusias dan kepercayaan. Ini sama pentingnya pada semua tingkat manajemen. Keterampilan konseptual termasuk kepala sekolah harus berpikir dan mengerti tentang situasi yang abstrak dan kompleks. Menggunakan ke-terampilan ini, kepala sekolah harus dapat melihat organisasi secara ke-seluruhan, memahami hubungan antara berbagai sub unit, dan memvisualisasikan bagaimana organisasi masuk ke dalam lingkungan yang lebih luas.

Berdasarkan uraian di atas dapat disintesiskan bahwa keterampilan manajerial adalah kecakapan seorang manajer dalam melaksanakan tugas-tugas manajerial yang 
dilihat ber-dasarkan pengetahuan dan kualitasnya dalam melaksanakan tugas-tugas yang menjadi tanggung jawabnya, dengan indikator: keterampilan konseptual, ke-terampilan manusiawi dan keterampilan teknis.

\section{Komunikasi Interpersonal}

Aktivitas manusia membutuhkan komunikasi dengan orang lain, siapapun dia dan apapun tugas dan pekerjaan yang digelutinya. Komunikasi dengan orang lain dapat menggunakan berbagai macam cara dan alat yang sederhana sampai pada penggunaan cara-cara modern. Tujuannya adalah untuk mem-peroleh pemahaman yang sama tentang sesuatu hal. Robbins (2013: 336) mengatakan bahwa: "communication must include both the transfer and the understanding of meaning." Berdasarkan kutipan di atas bahwa dalam komunikasi tercakup pentransferan dan pemahaman makna.

James L. Gibson et. al. (2012: 446), menjelaskan bahwa: "Interpersonal communication is the primary means of managerial communication; on a typical day, over three-fourths of a manager's communications occur in face-to-face interactions". Berdasarkan kutipan di atas bahwa komunikasi interpersonal me-rupakan alat primer dari komunikasi manajerial; pada hari tertentu, lebih dari tiga per empat komunikasi para manajer terjadi dalam interaksi tatap muka.

Menurut Kreps (2000: 50) men-definisikan komunikasi interpersonal sebagai berikut: Interpersonal communication is between two people (a dyad), usually face, although people can use communication media (such as telephone) to communicate interpersonally without being in each other's immediate presence. One of the most important outcomes of interpersonal communication is the development of human relationships.

Pengertian komunikasi interpersonal di atas, bahwa sesungguhnya orang-orang yang terlibat dalam komunikasi interpersonal terdiri dari dua orang, dan biasanya bertatap muka, meskipun orang-orang tersebut menggunakan media komunikasi untuk berkomunikasi secara pribadi tanpa kehadiran mereka secara bersama-sama. Salah satu hasil yang paling penting dari komunikasi interpersonal ini adalah perkembangan hubungan sesama, yang dapat mem-bangun hubungan sosial yang baik di antara individu organisasi.

Komunikasi antar personil dalam suatu organisasi seperti sekolah harus diawali dengan adanya keterampilan komunikasi interpersonal yang dimiliki oleh seorang pemimpin yaitu kepala sekolah, sehingga dapat mempengaruhi personil sekolah lainnya dalam berkomunikasi baik dalam bentuk pribadi maupun kelompok. Hal ini penting mengingat sekolah merupakan satu komunitas dengan tujuan yang sama.

Pertukaran informasi antara kepala sekolah dan guru serta personil sekolah lainnya hanya bisa terjadi apabila terjalin hubungan yang harmonis antara kepala sekolah dan personil sekolah lainnya atau antara atasan dengan bawahan. Hubungan yang harmonis akan me-mungkinkan kepala sekolah me-laksanakan kontrol di dalam kelas, meng-komunikasikan tentang revisi atau per-baikan pembelajaran, meng-komunikasikan penggunaan alat bantu mengajar, mengkomunikasikan tentang diagnosis kesulitan belajar siswa atau permasalahan siswa, dan lain-lain yang tentunya membutuhkan umpan balik, yang kesemuanya menuju pada ke-berhasilan sekolah itu sendiri.

Berdasarkan uraian di atas dapat di-sintesiskan bahwa komunikasi interpersonal adalah proses penyampaian pesan secara diadik dari komunikator kepada komunikan untuk mencapai kesepahaman makna, dengan indikator: kejelasan informasi, keterbukaan, kesamaan persepsi, keakraban, umpan balik.

\section{Budaya Mutu}

Budaya mutu menurut Westbrook sebagaimana dikutip oleh Katiliute dan Neverauskas (2009: 1069-1079) bahwa "Quality culture is the main ingredient in a successful TQM program". Berarti bahwa budaya mutu merupakan kunci utama untuk 
mencapai kesuksesan dalam program manajemen mutu terpadu. Pendapat tersebut mengisyaratkan betapa pentingnya budaya mutu dalam menyukseskan TQM. Dengan demikian manajemen mutu terpadu tidak akan berjalan jika budaya mutu tidak ada dalam suatu lembaga pendidikan seperti sekolah.

Menurut Stamelos dan Bartzakli (2013: 460) bahwa "Quality culture is an established feature of a system, its relationships with the communities of practice are reciprocal, and the one influences the other. Quality culture is more of a request, and less the reality, more evidence of a desire for change of attitude, then the community of practice appears to be a condition for the creation of a quality culture". Hal ini berarti bahwa budaya mutu adalah suatu ciri-ciri yang dibangun suatu sistem, hubungannya timbal balik dengan praktik bersama, dan saling mempengaruhi satu sama lain. Bagaimanapun, budaya mutu lebih banyak diminta, dan semakin sedikit realita, semakin banyak bukti dari keinginan untuk mengubah perilaku, lalu praktik bersama muncul menjadi suatu kondisi bagi penciptaan budaya mutu.

Sedangkan menurut David L. Goetsch dan Stanley Davis (2013: 83) bahwa: "A quality culture is an organizational value system that results in an environment that is conducive to the establishment and continual improvement of quality. It consists of values, traditions, procedures, and expectations that promote quality". Berdasarkan kutipan di atas bahwa budaya mutu merupakan suatu sistem nilai organisasional yang menghasilkan suatu lingkungan yang kondusif untuk pembangunan dan peningkatan berkelanjutan dari mutu. Itu terdiri dari nilai, tradisi, prosedur dan pengharapan yang memajukan mutu.

Berdasarkan uraian di atas dapat di-sintesiskan bahwa budaya mutu dapat diartikan sebagai aktivitas dalam memenuhi harapan pelanggan pada sekolah secara terus menerus sehingga menjadi suatu sistem nilai organisasi yang menghasilkan suatu lingkungan yang kondusif untuk pembangunan dan peningkatan ber-kelanjutan dari mutu, dengan indikator: nilai, tradisi, prosedur dan harapan.

\section{METODOLOGI PENELITIAN}

Pada penelitian ini digunakan metode survei, yaitu metode yang berusaha menjelaskan tentang adanya pengaruh variabel eksogen terhadap variabel endogen baik secara langsung maupun tidak langsung melalui variabel lainnya. Pendekatan yang digunakan dalam penelitian ini adalah pendekatan kuantitatif dengan menggunakan teknik analisis jalur (path analysis) atas data yang diperoleh dari lapangan.

Populasi target dalam penelitian ini adalah guru pada Sekolah Dasar Negeri di Kabupaten Lampung Utara berjumlah 419 orang guru. Sampel diambil sebanyak 205 orang guru dengan meng-gunakan teknik Simple Random Sampling. Jumlah tersebut diperoleh dengan menggunakan rumus Slovin pada taraf signifikan 5\%.

Teknik yang digunakan untuk men-dapatkan data penelitian dilakukan dengan menggunakan kuesioner skala lima. Kuesioner disusun berdasarkan teori-teori yang digunakan. Kuesioner di-sebarkan kepada guru dan kepala sekolah yang menjadi responden dalam penelitian ini.

Analisis data yang digunakan dalam penelitian ini adalah analisis deskriptif dan inferensial. Analisis deskriptif menyajikan karakteristik data dari masing-masing variabel dalam bentuk penyajian data, ukuran tendensi sentral dan ukuran pe-nyebaran data. Statistika inferensial yang digunakan untuk menguji hipotesis penelitian adalah dengan menggunakan analisis jalur.

\section{HASIL PENELITIAN DAN PEMBAHASAN}

Data yang diperoleh dari lapangan diolah dan telah melalui berbagai uji yang dipersyaratkan, maka tahapan se-lanjutnya dalam pengujian model kausalitas adalah 
melakukan analisis jalur (path analysis). Berdasarkan model kausal yang dibentuk secara teoretik akan diperoleh diagram analisis jalur dan kemudian dihitung nilai koefisien untuk setiap jalurnya.

Nilai yang perlu diketahui untuk per-hitungan selanjutnya adalah nilai korelasi sederhana yang disajikan dalam bentuk matriks koefisien korelasi sebagai berikut:

Tabel 1. Matriks Koefisien Korelasi Sederhana Antar Variabel

\begin{tabular}{|c|c|c|c|c|}
\hline Variabel & $\mathbf{X 1}$ & $\mathbf{X 2}$ & $\mathbf{X 3}$ & $\mathbf{Y}$ \\
\hline $\mathbf{X 1}$ & 1.0000 & 0,732 & 0,702 & 0,312 \\
\hline $\mathbf{X} 2$ & 0,732 & 1.0000 & 0,064 & 0,188 \\
\hline $\mathbf{X 3}$ & 0,702 & 0,064 & 1.0000 & 0,411 \\
\hline $\mathbf{Y}$ & 0,312 & 0,188 & 0,411 & 1.0000 \\
\hline
\end{tabular}

Berdasarkan hasil perhitungan koefisien determinasi pada tabel tersebut di atas, selanjutnya diperoleh nilai koefisien jalur sebagai berikut:

Tabel 2. Hasil Perhitungan dan Pengujian Koefisien Jalur

\begin{tabular}{|c|c|c|c|c|c|c|}
\hline Jalur & Determinasi & $\begin{array}{c}\text { Koefisien } \\
\text { Jalur }\end{array}$ & thitung $_{\text {hit }}$ & $\mathbf{t}_{\boldsymbol{a}=0,05}$ & $\mathbf{t}_{\mathrm{a}=0,01}$ & Keputusan \\
\hline $\mathrm{YX}_{1}$ & 0,517 & 0,312 & 9,955 & 1,9718 & 2,600 & Signifikan \\
\hline $\mathrm{YX}_{2}$ & 0,518 & 0,188 & 5,635 & 1,9718 & 2,600 & Signifikan \\
\hline $\mathrm{YX}_{3}$ & 0,600 & 0,411 & 4,064 & 1,9718 & 2,600 & Signifikan \\
\hline $\mathrm{X}_{3} \mathrm{X}_{1}$ & 0,451 & 0,702 & 12,059 & 1,9718 & 2,600 & Signifikan \\
\hline $\mathrm{X}_{3} \mathrm{X}_{2}$ & 0,658 & 0,064 & 0,873 & 1,9718 & 2,600 & $\begin{array}{c}\text { Tidak } \\
\text { Signifikan }\end{array}$ \\
\hline $\mathrm{X}_{2} \mathrm{X}_{1}$ & 0,380 & 0,732 & 11,470 & 1,9718 & 2,600 & Signifikan \\
\hline
\end{tabular}

Keterangan:

$t_{a=0,05}=(\alpha / 2 ; n-k-1)=(0,05 / 2 ; 205-3-1)=(0,025 ; 201)$, lihat tabel $t(1,9718)$

$\mathbf{t}_{\alpha=0,01}=(\alpha / 2 ; n-k-1)=(0,01 / 2 ; 205-3-1)=(0,005 ; 201)$, lihat tabel $t(2,600) n$

Selanjutnya hasil perhitungan di atas digambarkan ke dalam diagram jalur berikut:

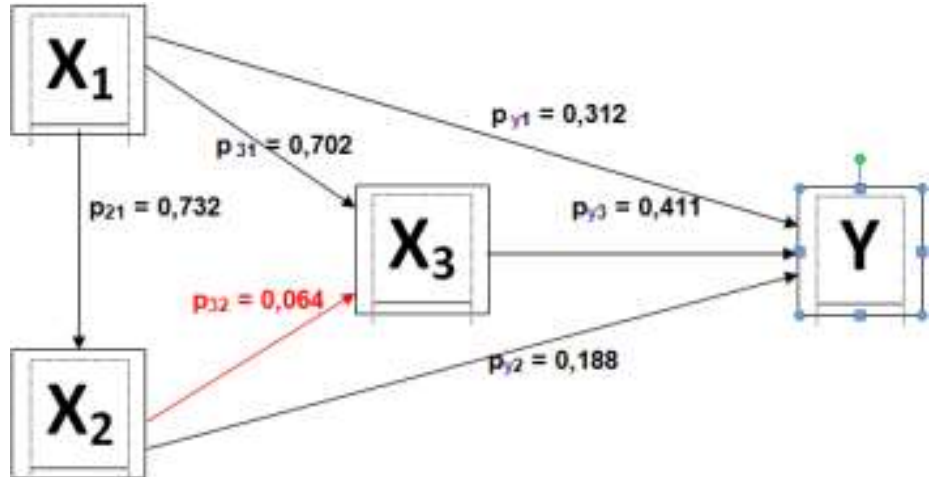

\section{Gambar 1. Model Hubungan Struktural Antar Variabel Berdasarkan Perhitungan Analisis Jalur}

Tabel dan gambar tersebut di atas me-nunjukkan koefisien jalur antara variabel eksogen dengan variabel endogen. Koefisien jalur antara keterampilan manajerial terhadap OCB $\left(p_{y 1}\right)$ sebesar 0,312 ; koefisien jalur antara komunikasi interpersonal terhadap OCB $\left(p_{y_{2}}\right)$ sebesar 0,188 ; koefisien jalur antara budaya mutu terhadap OCB $\left(p_{y 3}\right)$ sebesar 0,411 ; koefisien jalur antara keterampilan manajerial terhadap budaya mutu $\left(p_{31}\right)$ 
sebesar 0,702; dan koefisien jalur antara keterampilan manajerial terhadap komunikasi interpersonal $\left(\mathrm{p}_{21}\right)$ sebesar 0732. Apabila diuji dengan menggunakan uji t, didapat $t_{\text {hitung }}>$ $t_{\alpha=0,05}=1,9718$; maka koefisien jalur di atas menunjukkan angka yang signifikan seluruh variabel eksogen terhadap variabel endogen. Dengan demikian koefisien jalur antar variabel tersebut signifikan pada taraf $\alpha=0,05$.

Berdasarkan uraian di atas, maka dapat dilakukan pengujian hipotesis penelitian sebagai berikut:

a. Hipotesis Pertama: Keterampilan Manajerial $\left(X_{1}\right)$ berpengaruh langsung positif terhadap Organizational Citizenship Behavior $(\mathrm{Y})$, menyatakan hasil perhitungan diperoleh nilai koefisien jalur $p_{y 1}=0,312$ dengan $t_{\text {hitung }} 9,955$ dan $t_{\text {tabel }}$ pada taraf nyata $\alpha=0,05$ diperoleh $t_{\text {tabel }} 1,9718$. Karena $t_{\text {hitung }}=9,955>t_{\text {tabel(0,05) }}=1,9718 ;$ maka $H_{0}: \beta_{y 1}$ $\leq 0$ ditolak, dan $\mathrm{H}_{1}: \beta_{\mathrm{y} 1}>0$ diterima bahwa koefisien jalur $p_{\mathrm{y} 1}=0,312$ adalah signifikan pada taraf $\alpha=0,05$. Dengan hasil pengujian ditolaknya $\mathrm{H}_{0}$ dan diterimanya $\mathrm{H}_{1}$ maka dapat disimpulkan bahwa keterampilan manajerial $\left(X_{1}\right)$ berpengaruh langsung positif terhadap OCB (Y).

b. Hipotesis Kedua: Komunikasi Interpersonal $\left(\mathrm{X}_{2}\right)$ berpengaruh langsung positif terhadap Organizational Citizenship Behavior $(\mathrm{Y})$, menyatakan hasil perhitungan diperoleh nilai koefisien jalur $p_{y 2}=0,188$ dengan $t_{\text {hitung }} 5,635$ dan $t_{\text {tabel }}$ pada taraf nyata $\alpha=0,05$ diperoleh $t_{\text {tabel }} 1,9718$. Karena $t_{\text {hitung }}=5,635>t_{\text {tabel( } 0,05)}=1,9718 ;$ maka $H_{0}: \beta_{y 2}$ $\leq 0$ ditolak, dan $\mathrm{H}_{1}: \beta_{\mathrm{y}_{2}}>0$ diterima bahwa koefisien jalur $\mathrm{p}_{\mathrm{y} 2}=0,188$ adalah signifikan pada taraf $\alpha=0,05$. Dengan hasil pengujian ditolaknya $\mathrm{H}_{0}$ dan diterimanya $\mathrm{H}_{1}$ maka dapat disimpulkan bahwa komunikasi interpersonal $\left(\mathrm{X}_{2}\right)$ berpengaruh langsung positif terhadap OCB (Y).

c. Hipotesis Ketiga: Budaya Mutu $\left(X_{3}\right)$ berpengaruh langsung positif terhadap Organizational Citizenship Behavior $(\mathrm{Y})$, menyatakan hasil perhitungan diperoleh nilai koefisien jalur $p_{y_{3}}=0,411$ dengan $t_{\text {hitung }} 4,064$ dan $t_{\text {tabel }}$ pada taraf nyata $\alpha=0,05$ diperoleh $t_{\text {tabel }} 1,9718$. Karena $t_{\text {hitung }}=4,064>t_{\text {tabel(0,05) }}=1,9718$; maka $H_{0}: \beta_{y 3} \leq 0$ ditolak, dan $\mathrm{H}_{1}$ : $\beta_{\mathrm{y} 3}>0$ diterima bahwa koefisien jalur $p_{\mathrm{y} 3}=0,411$ adalah signifikan pada taraf $\alpha=0,05$. Dengan hasil pengujian ditolaknya $\mathrm{H}_{0}$ dan diterimanya $\mathrm{H}_{1}$ maka dapat disimpulkan bahwa budaya mutu $\left(\mathrm{X}_{3}\right)$ berpengaruh langsung positif terhadap OCB (Y).

d. Hipotesis Keempat: Keterampilan Manajerial $\left(X_{1}\right)$ berpengaruh langsung positif terhadap Budaya Mutu $\left(\mathrm{X}_{3}\right)$, menyatakan hasil perhitungan diperoleh nilai koefisien jalur $p_{31}=0,702$ dengan $t_{\text {hitung }} 12,059$ dan $t_{\text {tabel }}$ pada taraf nyata $\alpha=0,05$ diperoleh $t_{\text {tabel }}$ 1,9718. Karena $t_{\text {hitung }}=12,059>t_{\text {tabel }(0,05)}=1,9718$; maka $\mathrm{H}_{0}: \beta_{31} \leq 0$ ditolak, dan $\mathrm{H}_{1}$ : $\beta_{31}>0$ diterima bahwa koefisien jalur $p_{31}=0,702$ adalah signifikan pada taraf $\alpha=$ 0 ,05. Dengan hasil pengujian ditolaknya $H_{0}$ dan diterimanya $H_{1}$ maka dapat disimpulkan bahwa keterampilan manajerial $\left(X_{1}\right)$ ber-pengaruh langsung positif terhadap budaya mutu $\left(\mathrm{X}_{3}\right)$.

e. Hipotesis Kelima: Komunikasi Interpersonal $\left(\mathrm{X}_{2}\right)$ berpengaruh langsung positif terhadap Budaya Mutu $\left(\mathrm{X}_{3}\right)$, menyatakan hasil per-hitungan diperoleh nilai koefisien jalur $p_{32}=0,064$ dengan $t_{\text {hitung }} 0,873$ dan $t_{\text {tabel }}$ pada taraf nyata $\alpha=0,05$ diperoleh $t_{\text {tabel }}$ 1,9718. Karena $t_{\text {hitung }}=0,873<t_{\text {tabel }(0,05)}=1,9718$; maka $H_{0}: \beta_{32} \geq 0$ diterima, dan $H_{1}$ : $\beta_{32}<0$ ditolak bahwa koefisien jalur $p_{32}=0,064$ adalah tidak signifikan pada taraf $\alpha=$ 0,05 . Dengan hasil pengujian diterimanya $H_{0}$ dan ditolaknya $H_{1}$ maka dapat disimpulkan bahwa komunikasi interpersonal $\left(X_{2}\right)$ tidak berpengaruh langsung positif terhadap budaya mutu $\left(\mathrm{X}_{3}\right)$.

f. Hipotesis Keenam: Keterampilan Manajerial $\left(X_{1}\right)$ berpengaruh langsung positif terhadap Komunikasi Interpersonal $\left(\mathrm{X}_{2}\right)$, me-nyatakan hasil perhitungan diperoleh nilai koefisien jalur $p_{21}=0,732$ dengan $t_{\text {hitung }} 11,470$ dan $t_{\text {tabel }}$ pada taraf nyata $\alpha=0,05$ diperoleh $t_{\text {tabel }} 1,9718$. Karena $t_{\text {hitung }}=11,470>t_{\text {tabel(0,05) }}=1,9718$; maka $H_{0}: \beta_{21} \leq 0$ ditolak, dan $\mathrm{H}_{1}: \beta_{21}>0$ diterima bahwa koefisien jalur $\mathrm{p}_{21}=0,732$ adalah signifikan pada taraf $\alpha=0,05$. Dengan hasil pengujian ditolaknya $\mathrm{H}_{0}$ dan diterimanya $\mathrm{H}_{1}$ maka 
dapat disimpulkan bahwa keterampilan manajerial $\left(X_{1}\right)$ berpengaruh langsung positif terhadap komunikasi interpersonal $\left(\mathrm{X}_{2}\right)$.

Berdasarkan uraian pada uji hipotesis di atas, maka dapat diuraikan temuan penelitian ini, yaitu:

\section{Pengaruh Keterampilan Manajerial Terhadap OCB}

Terujinya hipotesis pertama, memper-kuat bahwa salah satu faktor yang mempengaruhi perilaku anggota organisasi (Organizational Citizenship Behavior) yaitu faktor personal yang melibatkan kepala sekolah. Keberhasilan suatu sekolah pada hakikatnya terletak pada efisiensi dan efektivitas penampilan se-orang kepala sekolah. Pada hal ini kepala sekolah sebagai seseorang yang diberi tugas untuk memimpin sekolah, kepala sekolah bertanggungjawab atas ter-capainya tujuan sekolah. Kepala sekolah diharapkan menjadi pemimpin dan inovator di sekolah.

Keterampilan manajerial kepala sekolah merupakan unsur yang paling berpengaruh dalam memunculkan perilaku OCB. Hal ini terlihat pada hasil pengujian dari koefisien jalur yang menerangkan bahwa ditolaknya $\mathrm{H}_{0}$ dan diterimanya $\mathrm{H}_{1}$ yang berarti temuan hasil penelitian bahwa keterampilan manajerial memiliki pengaruh langsung positif terhadap OCB. Efek tidak langsung melengkapi efek langsung dari OCB atas keterampilan manajerial kepala sekolah dan kinerja tugas melalui mekanisme karakteristik pekerjaan, motivasi intrinsik dan komitmen pada tujuan.

Terujinya pengaruh langsung positif keterampilan manajerial terhadap OCB, maka terdapat kaitan erat antara kedua variabel tersebut. Hal ini sesuai dengan hasil penelitian sebelumnya yang di-lakukan oleh Ziguang Chen, Norihiko Takeuchi dan Mitsuru Wakabayashi berjudul "Managerial Skill Utilization: Work Environment, Gender and Training Incentive" (2005: 786-808). Penelitian ini menyatakan bahwa pemanfaatan keterampilan manajerial menentukan keluaran dan kinerja organisasional, salah satunya adalah OCB.

Hasil penelitian ini menjadi penguat bahwa sebagai makhluk sosial, kepala sekolah mempunyai kemampuan untuk berempati kepada orang lain dan lingkungannya, dan menyelaraskan nilai-nilai yang dianutnya. Melalui nilai-nilai yang dimiliki, maka akan meningkatkan interaksi sosial yang lebih baik. Jika setiap individu kepala sekolah memiliki perilaku OCB, maka ia dapat mengendalikan perilakunya sendiri atau mampu memilih perilaku terbaik untuk kepentingan organisasi sekolahnya. Hal ini tentunya akan berimbas pada peningkatan kinerja sekolah secara keseluruhan.

\section{Pengaruh Komunikasi Interpersonal Terhadap OCB}

Terujinya hipotesis kedua, memper-kuat bahwa faktor keberhasilan sekolah dalam mencapai tujuan yang diinginkan itu ditentukan oleh kemampuan kepala sekolah dalam berkomunikasi dengan baik terutama komunikasi interpersonal, karena komunikasi interpersonal me-rupakan komunikasi yang sering di-gunakan sehari-hari di lingkungan sekolah.

Kualitas komunikasi interpersonal di-yakini sebagai prediktor Organizational Citizenship Behavior (OCB). Komunikasi interpersonal yang berkualitas tinggi akan memberikan dampak seperti me-ningkatnya kepuasan kerja, produktivitas dan kinerja sekolah. Hal ini terlihat pada hasil pengujian dari koefisien jalur yang menerangkan bahwa ditolaknya $\mathrm{H}_{0}$ dan diterimanya $\mathrm{H}_{1}$ yang berarti bahwa komunikasi interpersonal berpengaruh langsung positif terhadap OCB. Artinya, jika komunikasi interpersonal terjalin dengan baik, maka perilaku OCB kepala sekolah akan membaik pula.

Terujinya pengaruh langsung positif komunikasi interpersonal terhadap OCB, maka terdapat kaitan erat antara kedua variabel tersebut. Hal ini sesuai dengan hasil penelitian sebelumnya yang di-lakukan oleh Syahfarnas Adi Putrantoro berjudul "Pengaruh Kepemimpinan, Komitmen Organisasi dan Komunikasi Interpersonal Terhadap 
Organizational Citizenship Behavior Anggota Rotaract Club Semarang" (2014: 112). Hasil penelitian ini menunjukkan bahwa ter-dapat pengaruh langsung positif dan signifikan antara komunikasi interpersonal terhadap OCB.

Hasil penelitian ini menjadi penguat bahwa peranan dan fungsi yang ter-penting bagi kepala sekolah adalah perannya sebagai komunikator. Peran kepala sekolah sebagai komunikator harus dapat diwujudkan dengan baik supaya kepala sekolah dapat me-ningkatkan perilaku OCB dalam keseharian di sekolah, dan sadar untuk mematuhi peraturan yang dibuat oleh sekolah sehingga dapat menghasilkan kinerja yang bagus. Seorang kepala sekolah akan berpandangan positif ter-hadap bawahannya sehingga kepala sekolah akan banyak memberikan dukungan dan motivasi. Hal ini me-ningkatkan rasa percaya dan hormat bawahan terhadap kepala sekolah sehingga mereka termotivasi untuk me-lakukan lebih dari yang diharapkan untuk kemajuan sekolah.

\section{Pengaruh Budaya Mutu Terhadap OCB}

Terujinya hipotesis ketiga, memper-kuat bahwa peran kepala sekolah sebagai pimpinan merupakan faktor penting yang bertanggungjawab dalam memimpin per-baikan sekolah dan dituntut untuk melakukan upaya-upaya organisatoris dalam memperbaiki mutu di sekolah. Hal ini terlihat pada hasil pengujian dari koefisien jalur yang menerangkan bahwa ditolaknya $\mathrm{H}_{0}$ dan diterimanya $\mathrm{H}_{1}$ yang berarti bahwa budaya mutu memiliki pengaruh langsung positif terhadap Organizational Citizenship Behavior (OCB). Budaya mutu sebagai bentuk nyata dari upaya kepala sekolah untuk meningkatkan mutu pendidikan, yang meliputi: mutu layanan sekolah, mutu sarana prasarana sekolah dan mutu guru serta staf sekolah.

Terujinya pengaruh langsung positif budaya mutu terhadap OCB, maka terdapat kaitan erat antara kedua variabel tersebut. Sesuai dengan teori di atas, bahwa kecenderungan budaya mutu akan dapat mendorong perilaku OCB kepala sekolah. Artinya, partisipasi warga sekolah dalam menggapai tujuan sekolah, akan terwujud jika kepala sekolah mampu mempengaruhi, mengajak dan men-ciptakan lingkungan yang kondusif, yang memungkinkan warga sekolah merasa memiliki sekolah sebagai bagian yang tak terpisahkan dalam kehidupan mereka.

Hasil penelitian ini menjadi penguat bahwa budaya mutu tampak menjadi suatu istilah payung dimana meng-karakteristikkan prosedur dan tindakan yang ditujukan untuk pencapaian mutu dalam pendidikan OCB itu sendiri merupakan perilaku yang tidak dapat di-paksakan pada batas-batas pekerjaan dan tidak secara resmi menerima peng-hargaan tetapi mampu memberikan kontribusi bagi perkembangan produktivitas dan keefektifan organisasi yang berkaitan dengan budaya mutu. Perilaku OCB seperti itu yang dibutuhkan untuk mendukung kegiatan-kegiatan dalam organisasi sekolah yang tidak selalu dapat dilakukan secara formal melalui kegiatan rutin sekolah.

\section{Pengaruh Keterampilan Manajerial Terhadap Budaya Mutu}

Terujinya hipotesis keempat, memper-kuat bahwa faktor keterampilan manajerial kepala sekolah sangat di-butuhkan guna mendukung peningkatan budaya mutu. Kepala sekolah yang selalu membimbing guru dan mendengarkan keluhan bawahan cenderung memberikan efek positif terhadap mutu sekolah. Ke-terampilan manajerial kepala sekolah juga terkait erat pada komponen-komponen yang langsung berhubungan dengan pengelolaan sarana prasarana dan proses pendidikan yang dapat me-ningkatkan budaya mutu di sekolah tersebut.

Perhatian dunia pendidikan akan mutu pendidikan menjadi sesuatu hal yang baru jika dibandingkan dengan dunia bisnis. Oleh karena itu, budaya mutu dapat dipandang sebagai inovasi dalam pendidikan. Sosialisasi kepala sekolah menjadi hal yang penting dalam ke-berhasilan implementasi budaya mutu. Hal ini terlihat pada hasil pengujian dari koefisien jalur yang menerangkan bahwa ditolaknya $\mathrm{H}_{0}$ dan diterimanya $\mathrm{H}_{1}$ yang berarti, temuan penelitian menunjukkan bahwa keterampilan manajerial memiliki pengaruh 
langsung positif terhadap budaya mutu. Hal ini berarti bahwa semakin tinggi keterampilan manajerial yang dibutuhkan kepala sekolah, maka semakin banyak pula aspek dalam budaya mutu yang sesuai dengan keinginan setiap individu, dan begitu pula sebaliknya.

Terujinya pengaruh langsung positif keterampilan manajerial terhadap budaya mutu, maka terdapat kaitan erat antara kedua variabel tersebut. Sesuai dengan teori di atas bahwa keterampilan manajerial kepala sekolah diduga sangat besar pengaruhnya terhadap budaya mutu sekolah. Guru akan bersemangat dan bergairah dalam bekerja serta akan lebih berhati-hati dalam setiap tugas yang dilaksanakannya jika keterampilan manajerial kepala sekolah sudah di-terapkan dengan baik. Namun sebaliknya jika persepsi guru kurang bagus maka guru pun kurang termotivasi dalam me-laksanakan tugas, sehingga mutu dari sekolah tersebut akan berkurang juga.

Pada lingkungan sistem pendidikan, khususnya persekolahan, budaya mutu merupakan akuntabilitas publik. Setiap komponen pemangku kepentingan pendidikan (orang tua, masyarakat, dunia kerja, pemerintah) dalam peranan dan ke-pentingannya masing-masing memiliki ke-pentingan terhadap penyelenggaraan pendidikan yang bermutu.

Hasil penelitian ini menjadi penguat bahwa budaya mutu secara menyeluruh harus dilakukan dengan melibatkan semua pihak yang terkait mulai dari hulu sampai hilir, khususnya kepala sekolah dalam mencakup semua proses yang di-lakukan sesuai standar mutu (quality control). Budaya mutu dilakukan dalam satu prosedur tata kerja yang jelas, strategi, kerja sama dan kolaborasi antar pemangku kepentingan; dan dilakukan secara terus-menerus serta berke-lanjutan.

\section{Pengaruh Komunikasi Interpersonal Terhadap Budaya Mutu}

Terujinya hipotesis kelima, pada suatu organisasi khususnya sekolah, dimana proses komunikasi adalah proses yang pasti dan selalu terjadi. Komunikasi interpersonal merupakan sarana untuk mengadakan koordinasi antara berbagai sub sistem dalam sekolah. Sekolah yang berfungsi baik, ditandai oleh adanya kerja sama secara sinergis dan harmonis dari berbagai komponen. Komunikasi interpersonal antara kepala sekolah dengan bawahan ditandai dengan adanya pemahaman, kesenangan, pengaruh pada sikap dan tindakan, serta hubungan yang semakin baik. Makin baik komunikasi antara kepala sekolah dan stakeholder lainnya di-perkirakan dapat meningkatkan budaya mutu sekolah tersebut.

Berdasarkan temuan penelitian S.Hardjosoedarmo (2004: 92) ter-lihat pada hasil pengujian dari koefisien jalur yang menerangkan bahwa diterima $\mathrm{H}_{0}$ dan ditolaknya $\mathrm{H}_{1}$ yang berarti budaya mutu tidak dipengaruhi oleh komunikasi interpersonal. Hal ini sejalan dengan teori bahwa budaya mutu merupakan pola nilai, keyakinan dan harapan yang ditanamkan dan berkembang di kalangan anggota organisasi mengenai pekerjaannya untuk menghasilkan produk dan jasa yang berkualitas. Sehingga budaya mutu sangat sesuai diarahkan kepada bagaimana mengelola aktivitas suatu organisasi seperti sekolah. Maka sudah seyogyanya bila komunikasi interpersonal kepala sekolah tidak perlu lagi dibahas, karena komunikasi interpersonal kepala sekolah seharusnya sudah menjadi baik sebelum ia diangkat menjadi pimpinan sekolah.

\section{Pengaruh Keterampilan Manajerial Terhadap Komunikasi Interpersonal}

Terujinya hipotesis keenam, memper-kuat bahwa pada manajemen organisasi, faktor kehadiran seorang pemimpin sangat dibutuhkan sebab tanpa pemimpin maka organisasi akan tidak terkendali. Guna menjalankan tugasnya, seorang pemimpin perlu memiliki keterampilan manajerial yang baik agar dapat menjadi penunjuk arah keberlangsungan organisasi. Keterampilan manajerial yang baik mempengaruhi perilaku komunikasi interpersonal kepala sekolah pada stakeholder lainnya dalam organisasi sekolah. Pada rangka menjalankan fungsi-fungsi manajemen, seorang kepala sekolah perlu membimbing, meng-arahkan dan mengatur kegiatan bawahannya. Untuk itu, 
seorang kepala sekolah selalu melakukan komunikasi dengan bawahannya. Komunikasi ini merupakan suatu tahap kepemimpinan yang memindahkan ide-ide seseorang kepada orang lain untuk digunakan dalam fungsinya memimpin pekerjaan.

Komunikasi interpersonal merupakan komunikasi yang terjadi antara dua atau lebih orang dalam organisasi, sekaligus sebuah tindakan menyeluruh yang me-libatkan berbagai aspek demi ter-capainya hasil maksimal yang diperoleh lembaga. Ujung tombak pencapaian tujuan lembaga sangat tergantung pada keterampilan manajerial kepala sekolah. Hal ini terlihat pada hasil pengujian dari koefisien jalur yang menerangkan bahwa ditolaknya $\mathrm{H}_{0}$ dan diterimanya $\mathrm{H}_{1}$ yang berarti temuan hasil penelitian me-nunjukkan keterampilan manajerial memiliki pengaruh langsung positif ter-hadap komunikasi interpersonal. Temuan ini tentunya berkaitan dengan teori bahwa komunikasi interpersonal adalah komunikasi yang dibangun secara lancar, baik ke bawah, ke atas, horizontal atau interaktif.

Terujinya pengaruh langsung positif komunikasi interpersonal terhadap Organizational Citizenship Behavior, maka terdapat kaitan erat antara kedua variabel tersebut. Hal ini sesuai dengan hasil penelitian sebelumnya yang di-lakukan oleh $\mathrm{M}$. Tiwuk Rusmiyati (2012: 89), berjudul "Hubungan Keterampilan Manajerial Kepala Sekolah, Komunikasi Organisasi, dan Iklim Organisasi dengan Keefektifan Organisasi Sekolah Dasar di Gugus Mayor Metra, Kecamatan Denpasar Utara". Hasil penelitian menunjukkan bahwa terdapat hubungan yang signifikan secara simultan antara keterampilan manajerial kepala sekolah, komunikasi organisasi, dan iklim organisasi dengan keefektifan organisasi.

Hasil penelitian ini menjadi penguat bahwa pada saat melaksanakan kegiatan penyelenggaraan pendidikan, kepala sekolah diharapkan agar dapat ber-komunikasi dengan baik terhadap guru, siswa, komite sekolah, orang tua siswa dan diantara sesama kepala sekolah lainnya. Komunikasi yang baik ini pada gilirannya akan memudahkan kepala sekolah dalam meningkatkan ke-terampilan manajerialnya. Melalui perannya sebagai pemimpin, kepala sekolah harus mempunyai keterampilan manajerial untuk melakukan komunikasi interpersonal dengan baik agar mampu untuk mempengaruhi stakeholder yang terlibat dalam proses pendidikan yang akhirnya mencapai tujuan dan kualitas sekolah.

\section{KESIMPULAN}

Berdasarkan hasil analisa data dan perhitungan statistik, maka dari hasil penelitian ini menghasilkan temuan sebagai berikut: a. Terdapat pengaruh langsung positif antara keterampilan manajerial terhadap Organizational Citizenship Behavior. Dengan meningkatkan keterampilan manajerial kepala sekolah maka akan menyebabkan meningkatnya Organizational Citizenship Behavior di sekolah tersebut. b. Terdapat pengaruh langsung positif antara komunikasi interpersonal terhadap Organizational Citizenship Behavior. Dengan meningkatkan komunikasi interpersonal maka akan menyebabkan meningkatnya Organizational Citizenship Behavior di sekolah tersebut. c. Terdapat pengaruh langsung positif antara budaya mutu terhadap Organizational Citizenship Behavior. Dengan meningkatkan budaya mutu maka akan menyebabkan meningkatnya Organizational Citizenship Behavior di sekolah tersebut. d. Terdapat pengaruh langsung positif antara keterampilan manajerial terhadap budaya mutu. Dengan meningkatkan ke-terampilan manajerial kepala sekolah maka akan menyebabkan meningkatnya budaya mutu di sekolah tersebut. e. Terdapat pengaruh langsung positif antara keterampilan manajerial terhadap komunikasi interpersonal. Dengan meningkatkan keterampilan manajerial kepala sekolah maka akan menyebabkan meningkatnya komunikasi interpersonal di sekolah tersebut.

Berdasarkan temuan di atas, dapat disimpulkan bahwa variasi Organizational Citizenship Behavior SD Negeri di Kabupaten Lampung Utara dapat dijelaskan melalui variasi dari keterampilan manajerial, komunikasi interpersonal, dan budaya mutu. 


\section{Daftar Pustaka}

Adi Putrantoro, Syahfarnas. Pengaruh Kepemimpinan, Komitmen Organisasi dan Komunikasi Interpersonal Terhadap Organizational Citizenship Behavior Anggota Rotaract Club Semarang. Semarang: Universitas Diponegoro, 2014.

Alotaibi, A.G. "Antecedents of OCB: A Study of Public Personnel in Kuwait" Public Personnel Management, Vol. 30, No. 3, 2001.

Chen et.al. Managerial Skill Utilization: Work Environment, Gender, and Training Incentive, International Journal of Human Resource Management, Vol.16 No.5, 2005.

Chuadhry, Muhammad Asif dan Syed Manzoor Hussain Shah, Impact of Managerial Skills Learnt Through MA Educational Planning Management Programme of AIOU on The Performance of Institutional Heads, Turkish Online Journal of Distance Education, Vol.13 No.2, 2012.

Colquit, Jason A. et al., Organizational Behavior: Improving Performance and Commitment in the Work Place. New York: The McGraw-Hill Companies, 2009.

George, Jennifer M., dan Gareth R. Jones. Understanding and Managing Organizational Behavior, Sixth Edition. USA: Pearson Education Inc, 2012.

Gibson, James L. et. al., Organizations Behavior, Structure, Processes. (Fourteenth Edition). New York: McGraw-Hill, 2012.

Goetsch, David L., dan Stanley Davis, Quality Management for Organizational Excellence; Introduction to Total Quality, $7^{\text {th }}$ Edition.USA: Pearson Education Inc, 2013.

Hardjosoedarmo, S. Total Quality Mangement. Yogyakarta: Andi, 2004.

Katiliute, Egle dan Bronius Neverauskas, "Development Quality Culture in the Universities", Economic and Management”, Vol.14, 2009.

Kreps, Gary L. Organization Communication: Theory and Practice. New London: Longman, 2000.

Luthans, Fred. Organizational Behavior $12^{\text {th }}$ Edition. An Evidence Based Approach. New York: McGraw-Hill Companies, 2011.

Mulyasa. Manajemen Berbasis Sekolah. Konsep, Teori, dan Praktek. Bandung: PT. Remaja Rosdakarya, 2002.

Peraturan Menteri Pendidikan Nasional Nomor 13 Tahun 2007 tentang Kompetensi Kepala Sekolah/Madrasah.

Robbins, Stephen P. dan Timothy A. Judge. Organizational Behavior (Edition 15). USA: Pearson Education Inc, 2013.

Rusmiyati, M. Tiwuk. Hubungan Keterampilan Manajerial Kepala Sekolah, Komunikasi Organisasi, dan Iklim Organisasi dengan Keefektifan Organisasi Sekolah Dasar di Gugus Mayor Metra, Kecamatan Denpasar Utara (Denpasar, 2012).

Stamelos, Georgios \& Marianna Bartzakli, 'Good Practice' School Advisors in Greek Education: The Difficulty in Linking Collaborative Networks, Communities of Practice and Quality Culture, Teacher Development , Vol.17 No.4, 2013.

Sweeney, Paul D. dan Dean B. McFarlin, Organizational Behavior: Solutions For Management. New York: McGraw-Hill, 2002.

Wagner III, John A. dan Hollenbeck, John R., Organizational Behavior: Securing Competitive Advantage. New York: Michigan State University, 2010. 